\title{
GREENWASHING E SUA CONFIGURAÇÃO COMO PUBLICIDADE ENGANOSA E ABUSIVA SOB A PERSPECTIVA DO MICROSSISTEMA DE PROTEÇÃO E DEFESA DO CONSUMIDOR
}

\author{
GREENWASHING AND ITS CONFIGURATION AS MISLEADING AND ABUSIVE \\ ADVERTISING FROM THE PERSPECTIVE OF THE CONSUMER PROTECTION \\ MICROSYSTEM
}

\begin{abstract}
Fabrício Germano Alves
Doutor em Sociedad Democrática, Estado y Derecho pela Universidad del País Vasco / Euskal Herriko Unibertsitatea (UPV/EHU) - Espanha. Professor da Universidade Federal do Rio Grande do Norte (UFRN) fabriciodireito@gmail.com
\end{abstract}

\begin{abstract}
Resumo: A publicidade é uma atividade lícita, entretanto algumas espécies de publicidade foram expressamente proibidas pelo Código de Defesa do Consumidor (publicidade enganosa e abusiva). Configura-se greenwashing quando os fornecedores atribuem a si próprios ou a seus produtos e serviços, uma imagem de adequação ambiental e preocupação com o meio ambiente que não condiz com a realidade. Objetiva-se demonstrar como esse tipo de prática pode configurar publicidade enganosa e abusiva sob a perspectiva da legislação. Como metodologia utiliza-se de uma pesquisa aplicada, com abordagem hipotético-dedutiva e qualitativa, e com objetivo descritivo. A depender da forma em que a mensagem é veiculada, o greenwashing pode configurar tanto a publicidade enganosa (por comissão e por omissão) quanto a publicidade abusiva, nos termos do artigo 37 do Código de Defesa do Consumidor.
\end{abstract}

Palavras-chave: Greenwashing. Publicidade enganosa. Publicidade abusiva.

\begin{abstract}
Advertising is a lawful activity, however, some types of advertising have been expressly prohibited by the Consumer Protection Code (misleading and abusive advertising). Greenwashing is configured when the suppliers attribute to themselves or to their products and services, an image of environmental adequacy and concern with the environment that does not match reality. This work aims to demonstrate how this type of practice can configure misleading and abusive advertising from the perspective of the legislation. As a methodology, an applied research is used, with a hypothetical-deductive and qualitative approach, with a descriptive objective. Depending on the way the message is conveyed, greenwashing may configure both misleading advertising (by commission and by omission) and abusive advertising, under the terms of article 37 of the Consumer Protection Code.
\end{abstract}

Keywords: Misleading advertising. Abusive advertising. Consumer.

Para citar este artigo (ABNT NBR 6023:2018)

ALVES, Fabrício Germano. Greenwashing e sua configuração como publicidade enganosa e abusiva sob a perspectiva do microssistema de proteção e defesa do consumidor. Revista Thesis Juris - RTJ, São Paulo, v. 9, n. 1, p. 104-120, jan./jun. 2020. http://doi.org/10.5585/rtj.v9i1.16974. 


\section{Introdução}

O presente texto trata da prática do greenwashing na veiculação de mensagens publicitárias no contexto das relações de consumo, especificamente demostrando como a referida prática pode configurar as espécies de publicidade enganosa e abusiva nos termos da legislação brasileira de proteção e defesa do consumidor, que tem como núcleo a Lei n ${ }^{\circ}$ 8.078, de 11 de setembro de 1990, que instituiu o Código de Defesa do Consumidor (CDC).

Existe um grupo específico de consumidores que recebem a denominação de “consumidor verde". Nele estão incluídos aqueles que, além de buscar características como qualidade e preço, também consideram variáveis ambientais no momento de escolher os produtos e serviços, dando preferência aos que não agridam o meio ambiente, tanto na produção, quanto na distribuição, no consumo e no descarte final (CONSUMERS INTERNATIONAL/MMA/MEC/IDEC, 2005)

Assim, os consumidores que fazem parte desse grupo, quando se deparam com a infinidade de produtos e serviços disponibilizados no mercado, avaliam o impacto ambiental que pode ser causado a partir do seu consumo e optam por aqueles que se apresentam como os menores causadores de prejuízo ao meio ambiente, ou seja, os que forem mais ambientalmente responsáveis (MÉO, 2019).

Estão inseridos nessa categoria de consumidores tanto aqueles que se preocupam com as questões ambientais no momento da aquisição ou utilização dos produtos ou serviços (processo de consumo e relação pós-consumo) quanto os que atentam para o processos produtivos em si, considerando fatores como os recursos escassos que são consumidores em sua produção e o possível desperdício de matéria prima (PAIVA; PROENÇA, 2011).

Conforme pesquisa realizada pela MARKET ANALYSIS (2015), no período de 2010 a 2015 a quantidade de produtos que se autodeclaravam "verdes" no Brasil teve um crescimento de $478 \%$ (quase cinco vezes) e o número total de embalagens contendo sinais e mensagens indicando posturas simpáticas ao meio ambiente cresceu 296\% (quase três vezes). Esse crescimento provavelmente se deu em virtude do vislumbre do aumento do público de “consumidores verdes".

Atualmente (janeiro de 2020) o Brasil possui 41 certificações ambientais (ECOLABEL INDEX, 2020). Todavia, os selos provenientes das entidades certificadoras ainda não são encontrados na maioria dos produtos e serviços que são comercializados no mercado brasileiro. Possivelmente essa não popularização das certificações ambientais por meio do uso de selos tem uma dupla causa: por um lado grande parte dos fornecedores não demonstra tanto interesse 
em se adequar às regras para a obtenção dos referidos selos, e isso ocorre justamente em razão de não haver uma procura intensa e específica dos consumidores por produtos e serviços certificados; por outro lado, isso ocorre também devido à falta de informação e/ou consciência ambiental dos consumidores, que, em sua maioria, ainda não manifestam prioridades em relação ao consumo de produtos e serviços que detenham certificação ambiental.

Essa situação de crescimento da utilização do marketing ambiental ou marketing verde evidenciada na mencionada pesquisa realizada pela MARKET ANALYSIS em detrimento das devidas certificações dos produtos e serviços denota a configuração da prática de greenwashing, uma vez que os produtos e serviços que efetivamente atendessem às exigências das entidades certificadoras poderiam receber os respectivos selos identificadores das certificações ambientais.

O greenwashing na publicidade ocorre justamente quando os fornecedores anunciantes veiculam, por qualquer meio de comunicação, mensagens publicitárias atribuindo a seus produtos e serviços características que denotam que estes são ambientalmente adequados quando isso não corresponde à realidade. Há notícia bastante recente (fevereiro de 2020) sobre o banimento de anúncios publicitários de empresas em razão da prática de greenwashing (THE GUARDIAN, 2020).

Sendo assim, considerando que se trata de uma prática já bastante presente e que está em ascensão no mercado brasileiro, torna-se imprescindível o estudo não somente do seu conceito para permitir a sua identificação mas também de como esse tipo de prática pode configurar as espécies de publicidade ilícitas que são expressamente previstas no Código de Defesa do Consumidor (enganosa e abusiva).

O procedimento metodológico que servirá de base para a investigação será hipotéticodedutivo. Trata-se de uma pesquisa aplicada, uma vez que seus resultados são voltados para a prática. A abordagem será apenas qualitativa, pois o instituto será avaliado na perspectiva da legislação, sem a utilização de dados estatísticos sobre a incidência de casos de greenwashing nos anúncios publicitários veiculados no Brasil. Serão utilizadas a pesquisa bibliográfica e a pesquisa documental como procedimentos técnicos para a coleta de informações. O objetivo será descritivo a respeito da conformação do objeto pesquisado no ordenamento jurídico brasileiro. Por fim, será realizada uma avaliação formativa a fim de identificar pontos fortes e fracos na legislação e apontar possíveis melhorias.

Inicialmente serão trabalhados alguns conceitos básicos relacionados à configuração da relação jurídica de consumo, tratando especificamente dos elementos que a compõem (consumidor, fornecedor, produto e serviço), e também à publicidade em geral, bem como sobre 
as espécies de publicidade ilícita (enganosa e abusiva) que são previstas no artigo 37 do Código de Defesa do Consumidor.

Em seguida serão expostas as características do greenwashing a fim de permitir a compreensão do seu conceito e também se buscará identificar como esse tipo de prática pode ser utilizada na veiculação de mensagens publicitárias.

Por fim, serão trabalhados os conceitos de publicidade enganosa e abusiva a partir das definições trazidas pelo Código de Defesa do Consumidor, a fim de demonstrar em quais hipóteses a prática do greenwashing na comunicação publicitária pode configurar essas espécies publicitárias que são expressamente proibidas pelo artigo 37, caput do Código de Defesa do Consumidor.

\section{Relação jurídica de consumo e publicidade}

O artigo $5^{\circ}$, inciso XXXII da Constituição Federal de 1988 trouxe a seguinte determinação: “O Estado promoverá, na forma da lei, a defesa do consumidor”. Além disso, a “defesa do consumidor" foi instituída como um dos princípios gerais norteadores da atividade econômica (artigo 170, inciso V, Constituição Federal). Mas foi apenas com a promulgação da Lei $\mathrm{n}^{\circ} 8.078$ de 11 de setembro de 1990, que instituiu o Código de Defesa do Consumidor (CDC), que as relações de consumo receberam uma regulamentação específica. Com a promulgação do referido Código considera-se que foi instituído um verdadeiro microssistema de proteção consumerista no Brasil, dotado de princípios e regras próprias.

A identificação da relação jurídica de consumo é o critério básico para determinar o âmbito de aplicação não somente do Código de Defesa do Consumidor, mas também de toda a normatização protetiva do consumidor (MIRAGEM, 2019). Assim, não sendo identificada no caso prático a natureza consumerista, a relação deve ser regida por outro arcabouço normativo, a exemplo da Lei n ${ }^{\circ}$ 10.406, de 10 de janeiro de 2002, que instituiu o Código Civil.

O conceito da relação jurídica de consumo é obtido a partir da conjugação de seus elementos constitutivos: elementos subjetivos (consumidor e fornecedor), elementos objetivos (produto e serviço) e elemento causal ou finalístico (destinação final).

No que diz respeito aos elementos subjetivos, a caracterização de somente um dos sujeitos da relação, independentemente ser consumidor ou fornecedor, sem a concomitante caracterização do outro polo nos termos da conceituação adotada, implica em configuração de contrato de natureza não consumerista (COELHO, 1994). Essa mesa consequência se revela quando houver revenda ou repasse do produto ou serviço adquirido, em razão do fato de que 
em tais hipóteses não ser possível verificar a qualidade de destinatário final, exigida para a qualificação como consumidor.

O conceito jurídico de consumidor pode ser obtido a partir das quatro definições trazidas pelo CDC. Assim, são considerados consumidores diretos ou stricto sensu todas as pessoas físicas ou jurídicas, que venham a adquirir ou utilizar, um produto ou serviço, como destinatárias finais (artigo $2^{\circ}$, caput); por outro lado, a partir de uma perspectiva indireta ou lato sensu, classificam-se como consumidores por equiparação, a coletividade de pessoas, ainda que indetermináveis, que intervier em uma relação de consumo (artigo $2^{\circ}$, parágrafo único), todas as vítimas (bystanders) dos acidentes de consumo (artigo 17), e ainda todas as pessoas, mesmo que indetermináveis, que forem expostas às práticas comerciais previstas no Capítulo $\mathrm{V}$ do CDC (artigo 29).

Dentre as possibilidades de caracterização da relação jurídica de consumo tem-se como foco para a discussão da problemática do greenwashing o artigo 29 do Código de Defesa do Consumidor, que equipara à figura do consumidor todas as pessoas, independentemente de serem determináveis ou não, que são expostas às práticas comerciais previstas no Capítulo no qual está inserido (v.g., oferta, publicidade, práticas abusivas, cobrança de dívidas, e as condutas referentes aos bancos de dados e cadastro de consumidores).

Essa equiparação assume destaque em relação ao greenwashing pois é com fundamento nela que os consumidores podem ser protegidos sem que tenham necessariamente adquirido ou utilizado efetivamente um determinado produto ou serviço. É importante destacar aqui que a tutela dos interesses do consumidor pode assumir duas vertentes: uma individual e uma coletiva (ACOSTA ESTÉVEZ, 1995). A vertente coletiva é a mais indicada para a proteção de um maior número de consumidores de maneira mais célere e eficaz.

O conceito de fornecedor compreende igualmente as pessoas físicas e jurídicas, públicas e privadas, nacionais e internacionais, abrangendo inclusive os entes despersonalizados, desde que desenvolvam quaisquer das atividades previstas no artigo $3^{\circ}$, caput do CDC ("produção, montagem, criação, construção, transformação, importação, exportação, distribuição ou comercialização de produtos ou prestação de serviços”), de maneira habitual e/ou profissional.

$\mathrm{O}$ produto é definido no artigo $3^{\circ}, \S 1^{\circ}$ do $\mathrm{CDC}$ como qualquer bem colocado à disposição do consumidor no mercado, independentemente de ser móvel ou imóvel, material ou imaterial etc. Não se exige que ele seja oferecido em troca de uma contraprestação de natureza remuneratória. Assim, pode-se concluir que os produtos fornecidos a título de "amostra grátis" encontram-se igualmente tutelados pelo microssistema consumerista. 
$\mathrm{O}$ artigo $3^{\circ}, \S 2^{\circ}$ do CDC apresentou uma definição de serviço como qualquer atividade fornecida no mercado, dentre as quais estão inseridas as de natureza bancária, financeira, de crédito e securitária, desde que seja exercida mediante remuneração, excluindo-se apenas as prestações decorrentes de relações de caráter laboral.

A comunicação publicitária é um dos principais instrumentos que os fornecedores utilizam para aproximar os consumidores dos seus produtos e serviços. Conforme o objetivo da campanha a publicidade pode ser classificada em duas modalidades: promocional e institucional ou corporativa. A publicidade promocional tem o objetivo de divulgar determinados produtos ou serviços especificamente, ao passo que a publicidade institucional ou corporativa tem a finalidade de propagar somente a entidade empresarial do fornecedor ou a sua marca (ALVES, 2013). Em ambos os casos é possível a utilização do greenwashing.

Em seu artigo 37, caput o Código de Defesa do Consumidor proibiu expressamente toda publicidade enganosa ou abusiva. Com isso, o legislador buscou combater essas espécies de comunicação publicitária que são nefastas não somente aos consumidores, mas ao mercado de consumo como um todo, e reflexamente instituiu aos fornecedores anunciantes o dever de cuidar para que a publicidade cumpra licitamente seus propósitos, sendo veraz e condizente com os valores sociais consagrados.

\section{Conceituação do Greenwashing e forma de utilização dessa prática na publicidade}

Considerando um mercado cada vez mais marcado pelo fenômeno do consumo identitário, no qual os critérios de seletividade do consumidor são alinhados à identificação que eles possuem com os valores que são apregoados pelas marcas, cada vez mais os fornecedores procuram distinguir seus produtos e serviços ou até mesmo as próprias empresas em relação às demais da sua categoria a partir de elementos de diferenciação em relação aos concorrentes.

Esses elementos de diferenciação são os principais pilares da construção da identidade do fornecedor, que é desenvolvida no ambiente do mercado concorrencial por meio de ações de marketing que agem diretamente na formação da identidade (KAMINSKI, 2010). E é justamente a partir dessa identidade que os fornecedores anunciantes procuram atrair os consumidores que com ela se identificam. No caso do greenwahsing, os consumidores que possuem inclinação pela causa ambiental.

Ao lado da busca pela criação de identidade dos fornecedores para atender a um grupo de consumidores inseridos em um processo de identificação existe um cenário de consumismo 
que, ao passo em que viabiliza o processo de individualização, tende a ser predatório, apropriando-se dos recursos naturais e destruindo o meio ambiente (LEAL, 2019)

O meio ambiente é considerado um bem jurídico e autônomo. Este, pode sem compreendido como as ligações de um conjunto de elementos naturais, artificiais e culturais que são capazes de propiciar o desenvolvimento equilibrado da vida em todas as suas formas (SILVA, 2019).

Previsto expressamente no artigo 225, caput da Constituição Federal, o meio ambiente ecologicamente equilibrado é um direito de todos, considerado bem de uso comum do povo e essencial à sadia qualidade de vida. $\mathrm{O}$ mesmo dispositivo constitucional instituiu ao Poder Público e à coletividade o dever de defendê-lo e preservá-lo para as presentes e futuras gerações.

Em razão do surgimento de um público consumidor que não somente tem interesse nas questões ambientais, mas possui uma verdadeira predileção por produtos e serviços que demonstrem empatia pela causa da manutenção do meio ambiente ecologicamente equilibrado ("consumidor verde"), utilizar uma informação nesse sentido na publicidade tornou-se uma estratégia de marketing bastante comum no mercado.

O problema ocorre quando os fornecedores anunciantes se utilizam desse tipo de estratégia, veiculando nas mensagens publicitárias informações que denotam o seu engajamento ambiental, quando na verdade esse engajamento não existe, ou seja, constrói-se uma imagem ecologicamente correta sem a existência de um real compromisso ambiental. Assim ocorre o greenwashing.

Trata-se de uma prática na qual são falsamente atribuídas determinadas características a produtos e/ou serviços, no sentido de que eles são ambientalmente corretos ou adequados em algum aspecto, a fim de despertar o interesse do público consumidor que tem empatia pela causa ambiental.

O interesse desses consumidores é despertado no momento em que o fornecedor anunciante declara que os seus produtos e/ou serviços são mais vantajosos para toda a sociedade devido ao fato de causarem menos prejuízo ambiental. Sendo assim, eles optam por adquirir ou utilizar esses produtos ou serviços em detrimento de quaisquer outros que possam estar disponíveis no mercado (MÉO, 2019).

É possível que o greenwashing seja utilizado em uma comunicação publicitária que não seja relacionada especificamente a nenhum produto ou serviço, mas diretamente ao próprio fornecedor (publicidade institucional ou corporativa), no intuito de introduzir nos consumidores a concepção de que a entidade empresarial ou sua marca possui um perfil ambientalista e assim 
despertar indiretamente um interesse em relação a todos os seus produtos e serviços de modo geral.

Assim, os consumidores são enganados tanto em relação aos benefícios ambientais de um produto ou serviço quanto em relação às práticas ambientais da própria empresa (PARGUEL; BENOÎT-MOREAU; RUSSELL, 2015).

No Brasil sugere-se a utilização da expressão "maquiagem verde" para tratar da prática de greenwashing, pois o termo "maquiagem" já é amplamente utilizado, inclusive por órgãos públicos, nos casos em que há camuflagem de determinadas características de produtos e serviços (BRASIL, 2013).

A partir do desenvolvimento de pesquisas envolvendo a prática do greenwashing, foram identificados os chamados "Sete Pecados do Geenwashing” (Seven Sins of Greenwashing) para ajudar os consumidores a avaliar as características relacionadas ao meio ambiente que são atribuídas a produtos e serviços e identificar a ocorrência da prática de greewashing (TERRACHOICE, 2010).

Pecado do trade-off ${ }^{1}$ escondido (Sin of the hidden trade-off). Existe uma alegação de que o produto/serviço é "verde" ou ambientalmente correto (alegação ambiental) baseando-se apenas em um conjunto restrito de atributos, sem considerar outras questões ambientais importantes. V.g., destaca-se que o produto é produzido a partir de madeira reflorestada, mas omite-se a grande emissão de gases poluentes que ocorre a partir do seu processo de fabricação. E também o caso em que o anúncio publicitário não informa os efeitos da produção e do consumo relacionado a todo o ciclo de vida do produto, mas somente a uma determinada fase, desprezando aquelas que trazem malefícios ao meio ambiente (GARCIA, 2016).

Pecado da falta de provas (Sin of no proof). Apresentam-se benefícios ambientais desacompanhados da forma de acesso às informações que os fundamentam ou de uma certificação confiável de uma terceira entidade. V.g., um fornecedor de refrigerantes que alega que suas garrafas de vidro são reaproveitadas na fabricação de novos produtos, mas que não demonstra (omissão) ou permite que os consumidores tenham acesso (por sigilo) à forma que isso ocorre.

Pecado da vagueza (Sin of vagueness). Trata-se de uma informação que é tão imprecisa ou abrangente que o seu verdadeiro significado pode ser mal compreendido pelos

\footnotetext{
${ }^{1} \mathrm{O}$ termo da língua inglesa trade-off implica uma situação na qual ocorre ao mesmo tempo uma perda e um ganho. Perde-se em algum aspecto, mas ao mesmo tempo ganha-se em outro. Pode ocorrer também em sentido inverso, quando resolve-se um problema de alguma forma (ganho) que acaba acarretando um outro problema (perda).
} 
consumidores. V.g., um produto que pode ser nocivo ao meio ambiente em grandes quantidades é apresentado como "verde" simplesmente por ser natural.

Pecado de adorar falsos rótulos (Sin of worshiping false labels). Um produto ou serviço é acompanhado de palavras ou imagens que transmitem a impressão de que foram chancelados por um terceiro (geralmente no sentido de alguma garantia de qualidade), quando essa chancela simplesmente não existe. V.g., o produto ou serviço é acompanhado de um selo ambiental de uma entidade que não existe, é falsificado ou até mesmo foi criado pelo próprio fornecedor.

Pecado da irrelevância (Sin of irrelevance). Existe uma alegação ambiental que pode até mesmo ser verdadeira, contudo, não se trata de algo importante ou efetivamente útil aos consumidores que buscam preferencialmente produtos ambientalmente corretos. V.g., o rótulo do produto ressalta características que são próprias de toda a categoria de produtos da mesma natureza, ou seja, é o caso de um produto de origem vegetal que utiliza em seu rótulo a expressão "sem lactose" (qualidade inerente aos produtos de origem vegetal).

Pecado do menor entre dois males (Sin of lesser of two evils). Há uma alegação ambiental que pode ser verdadeira em relação a categoria do produto ou serviço, entretanto, gera o risco de distrair os consumidores no que tange aos maiores impactos ambientais da categoria como um todo. V.g., é lançado no mercado uma versão com maior economia de combustível fóssil para um veículo de transporte individual que sabidamente é altamente poluente.

Pecado de mentir (Sin of fibbing). Alegações ambientais que são simplesmente falsas. V.g., o fornecedor deliberadamente atribui a seus produtos e serviços características ambientais que eles não possuem, tais como: ser proveniente de material reciclado, não ser testado em animais etc.

Em razão da sua própria natureza de falsa, o greenwashing implica uma violação ética, pois quando uma instituição deliberadamente induz seus interlocutores ao erro por meio do discurso, cria-se um conflito racional e compromete-se a autonomia e a coerência da escolha (PAGOTTO, 2013).

O greenwashing tem o poder de afetar negativamente a chamada "intenção de compra verde", que é a probabilidade subjetiva de os consumidores adquirirem produtos e serviços ambientalmente adequados, e também de causar dano às marcas "verdes", que possuem um valor patrimonial agregado em razão dessa característica (AKTURAN, 2018).

Quando é utilizado na publicidade o greenwashing pode ser considerado uma prática ilícita sob a perspectiva do microssistema consumerista, seja em razão da enganosidade ou da 
abusividade que lhe são inerentes. No tópico seguinte será analisado especificamente como ocorre essa configuração.

\section{Enganosidade e abusividade na prática do Greenwashing na publicidade}

Antes de adentrar na discussão a respeito de como se configura a enganosidade e a abusividade na prática do greenwashing na publicidade é importante frisar que, tanto a publicidade enganosa quanto a publicidade abusiva configuram igualmente hipótese de prática abusiva, uma vez que, embora não haja previsão legal expressa nesse sentido no Código de Defesa do Consumidor, o rol de práticas abusivas elencado no artigo 39 do referido diploma legal não possui natureza exaustiva, isto é, trata-se de um rol meramente exemplificativo. Essa conclusão pode ser obtida a partir da interpretação da expressão "dentre outras práticas abusivas" contida no mencionado dispositivo.

Na qualidade de prática abusiva a veiculação de anúncios publicitários enganosos ou abusivos pode ser sancionada administrativamente, sem prejuízo das sanções de natureza civil e penal, por quaisquer das entidades que atuem na defesa do consumidor e que tenham competência para tanto, a exemplo dos PROCONs e da Secretaria Nacional do Consumidor SENACON. As sanções administrativas encontram-se previstas no artigo 56 do Código de Defesa do Consumidor, mas há possibilidade de outras serem definidas em normas específicas.

Além disso, a veiculação de peças publicitárias que venham a configurar hipótese de publicidade enganosa ou abusiva segundo os critérios definidos pelo Código de Defesa do Consumidor constitui também crime contra as relações de consumo (artigos 63, 64, 65, 66, 67 e 68 do CDC). Saliente-se que a política criminal que permite a responsabilização penal decorrente da publicidade ilícita deve ser aplicada com fundamento nos princípios gerais do Direito Penal Econômico, pois os delitos publicitários estão inseridos no grupo dos delitos contra a ordem socioeconômica (SANTAELLA LÓPEZ, 1981).

Ainda no que diz respeito à tutela penal da publicidade, é preciso deixar claro que, diferentemente do que ocorre com a responsabilização civil e administrativa nas relações de consumo (responsabilidade objetiva), a responsabilidade penal do agente possui natureza subjetiva, ou seja, somente pode ser atribuída quando restar provada a sua culpa lato sensu, que pode ser na modalidade do dolo ou da culpa stricto sensu (negligência, imprudência ou imperícia) (LAVORENTI; GENOFRE; SILVA, 2008).

Assim, dependendo da forma em que é veiculada a mensagem publicitária, o greenwashing ou maquiagem verde pode enganar o consumidor (induzindo-o a erro) ou até 
mesmo incentivar condutas prejudiciais ao meio ambiente, caracterizando assim tanto a publicidade enganosa como a publicidade abusiva (MÉO, 2019), que podem ser apenadas com sanções administrativas e também gerar repercussões na seara criminal (CRIVELLARI, 2012).

No ordenamento jurídico brasileiro o conceito de publicidade enganosa pode ser compreendido a partir da interpretação da definição contida no artigo 37, §1 $1^{\circ}$ do Código de Defesa do Consumidor (publicidade enganosa por comissão) juntamente com a definição trazida no artigo 37, $\S 3^{\circ}$ do mesmo Código (publicidade enganosa por omissão). Ademais, temse como norte também a disposição normativa contida no artigo $27, \S 2^{\circ}$ do Código Brasileiro de Autorregulamentação Publicitária (BRASIL, 1980), o qual determina que o anúncio não deverá conter informações de texto ou apresentação visual capaz de induzir o consumidor a engano, seja direta ou indiretamente, por implicação, omissão, exagero ou ambiguidade, em relação ao produto anunciado, ao anunciante ou seus concorrentes, ou ainda quanto à natureza do produto, sua procedência, composição ou finalidade.

Conforme o disposto no artigo $37, \S 1^{\circ}$ do Código de Defesa do Consumidor, considerase enganosa "qualquer modalidade de informação ou comunicação de caráter publicitário, inteira ou parcialmente falsa, ou, por qualquer outro modo, mesmo por omissão, capaz de induzir em erro o consumidor". Esse erro pode ser a respeito da da natureza, características, qualidade, quantidade, propriedades, origem, preço ou de quaisquer outros dados sobre produtos e serviços. É importante destacar que, conforme a referida redação do Código, considera-se enganosa tanto a publicidade que engana efetivamente (induz o consumidor em erro) quanto a que tem a capacidade de enganar (PASQUAU LIAÑO, 1992), em outras palavras, para a caracterização da publicidade enganosa não se exige a produção de um dano, erro ou engano efetivo, mas apenas que a mensagem seja suscetível de enganar (BOTANA GARCÍA; RUIZ MUÑOZ, 1999). Essa é a modalidade de publicidade enganosa por comissão.

O greenwashing pode configurar publicidade enganosa por comissão quando, por exemplo, o conteúdo de um anúncio publicitário possuir a capacidade de induzir o consumidor em erro no sentido de acreditar que um determinado produto não gera nenhum passivo ambiental, ou seja, não causa nenhum dano ao meio ambiente quando na verdade ele causa. Outro exemplo seria uma peça publicitária que apresenta uma certificação ambiental falsa que induz o consumidor a acreditar que o produto passou por um sistema de certificação e foi considerado ambientalmente adequado, o que na realidade não ocorreu. Seria igualmente o caso do fornecedor anunciante que alega que o seu produto é $100 \%$ natural, mesmo que tenha passado por um processo de industrialização. 
Já o artigo 37, $3^{\circ}$ do Código de Defesa do Consumidor instituiu a definição de publicidade enganosa por omissão que ocorre quando o fornecedor anunciante "deixar de informar sobre dado essencial do produto ou serviço". A prática do greenwashing pode configurar esse tipo de publicidade quando o fornecedor informa que o produto possui um menor teor de alguma substância que causa danos ambientais, porém deixa de informar que de qualquer maneira o consumo daquele produto gera graves danos ao meio ambiente. Assim, igualmente o consumidor é induzido a erro ao acreditar que se trata de um produto não nocivo.

Quando os fornecedores anunciantes se utilizam de quaisquer dessas espécies de publicidade enganosa (por comissão ou por omissão) esse tipo de conduta pode causar graves prejuízos, seja por induzir os consumidores a terem despesas com objetos inúteis ou perigosos, criar necessidades artificiais ou distorcer a concorrência entre as empresas e afetar o interesse público (CORREIA, 2005).

A publicidade abusiva é definida no artigo $37, \S 2^{\circ}$ do Código de Defesa do Consumidor, que instituiu o seguinte rol de categorias: a) discriminatória de qualquer natureza, b) que incite à violência, c) que explore o medo ou a superstição, d) que se aproveite da deficiência de julgamento e experiência da criança, e) que desrespeita valores ambientais, e f) que seja capaz de induzir o consumidor a se comportar de forma prejudicial ou perigosa à sua saúde ou segurança.

Em virtude da expressão "dentre outras" que é trazida no referido dispositivo do Código, pode-se concluir que o rol de categorias publicitárias que são consideradas abusivas é meramente exemplificativo (numerus apertus) (CASADO, 2006) e não taxativo ou exaustivo (numerus clausus). Sendo assim, o legislador deixa ao alvedrio do intérprete-aplicador a tarefa de identificar, a partir das situações concretas que se desenvolvem no mercado, quais delas podem ser consideradas como praticas abusivas nos termos da normatização de proteção do consumidor.

O greenwashing na publicidade pode configurar abusividade pelo menos de duas formas. A primeira é quando há um desrespeito ou uma violação aos valores ambientais. Seria o caso de um anúncio publicitário que instiga o consumo a adquirir ou utilizar um determinado produto ou serviço de maneira desenfreada e irracional, incompatível com os padrões de consumo sustentável.

No momento em que os fornecedores se utilizam de técnicas enganosas como o greenwashing para atrair a atenção dos "consumidores verdes", eles acabam desviando estes consumidores de outros fornecedores que, de fato, estão realmente engajados na causa ambiental e se encontram devidamente certificados. Assim, na medida em que se retira do 
consumidor o poder real de escolher produtos e serviços ambientalmente corretos, com base em informações falsas, os fornecedores que utilizam o greenwashing acabam por contribuir negativamente para a manutenção do meio ambiente ecologicamente equilibrado (consagrado como direito fundamental no artigo 225 da Constituição Federal), violando indiretamente valores ambientais, por meios culturais (MILARÉ, 2018).

A segunda forma que o greenwashing poderia configurar hipótese de publicidade abusiva seria ao induzir o consumidor a se comportar de forma prejudicial ou perigosa à sua saúde. Este seria o caso de uma comunicação publicitária que estimula o consumo de determinado produto a um ponto que venha a causar danos à saúde do consumidor. Note-se que a abusividade é aferida em abstrato, ou seja, consiste em simplesmente "induzir". Isso quer dizer que, para a configuração da abusividade não é necessário que o consumidor tenha adotado o comportamento prejudicial ou perigoso, ou ainda que tenha efetivamente sofrido qualquer espécie de dano à sua saúde em decorrência de tal comportamento.

Quando ocorre a enganosidade ou a abusividade na publicidade por meio do greenwashing, não somente os consumidores que estariam buscando especificamente por produtos mais ambientalmente corretos são prejudicados, mas em última instância é o próprio meio ambiente ecologicamente equilibrado (bem jurídico protegido constitucionalmente no art. 225 da Constituição Federal) que é vilipendiado pela conduta dos fornecedores.

\section{Conclusão}

A configuração da relação jurídica de consumo ocorre quando se verifica a presença de todos os seus elementos constitutivos: consumidor e fornecedor (elementos subjetivos), produto e serviço (elementos objetivos) e destinação final (elemento causal ou finalístico). Esse tipo de relação é regido pelo microssistema consumerista, que tem como peça principal e primordial o Código de Defesa do Consumidor (Lei $n^{\circ}$ 8.078/1990). Assim, não sendo identificada a presença dos referidos elementos, aplicar-se-á ao caso

No contexto das relações de consumo os fornecedores se utilizam da comunicação publicitária para estimular o consumo de seus produtos e serviços. Inclusive, a simples exposição a um anúncio publicitário já tem o condão de caracterizar uma relação de natureza consumerista por equiparação (artigo 29, CDC).

É justamente com fundamento no referido dispositivo que se torna possível a tutela do consumidor em relação à prática de greenwashing na publicidade, sem que necessariamente o ele tenha adquirido ou utilizado efetivamente algum produto ou serviço. Inclusive, a referida 
tutela pode ocorrer no âmbito individual ou coletivo, sendo este último mais eficiente para a proteção do maior número de consumidores com mais efetividade e celeridade.

A veiculação de mensagens de natureza publicitária é uma atividade lícita. O problema ocorre quando essas mensagens possuem um conteúdo que desconsidera os limites impostos pela legislação. É justamente isso que ocorre no caso de utilização do greenwashing na publicidade.

Essa utilização muitas vezes é impulsionada pelo desejo dos fornecedores em se destacar dos demais concorrentes considerando o fenômeno do consumo identitário, no qual os consumidores adotam como critério de escolha de seus produtos e serviços a identificação que possuem em relação aos fornecedores. Assim, o greenwashing é utilizado como prática publicitária para tentar atrair justamente o grupo específico de consumidores que se identifica com a causa ambiental.

Esse tipo de prática se verifica quando os fornecedores, por meio de anúncios publicitários, atribuem a si mesmos ou a seus produtos e/ou serviços, características que denotam uma postura ambientalmente correta ou adequada, quando isso não condiz com a realidade. Dessa forma, cria-se uma falsa concepção na mente dos consumidores que foram levados a adquirir ou utilizar os produtos ou serviços anunciados justamente em razão da característica "verde" ou ecologicamente correta que os foi apresentada na publicidade, ocasionando danos não somente individuais, mas também ao próprio meio ambiente.

Assim, em razão do fato de induzir ou pelo menos ter a capacidade de induzir em erro os consumidores, bem como de desrespeitar valores ambientais ou ainda induzir os consumidores a se comportarem de forma prejudicial ou perigosa à sua saúde, os anúncios publicitários nos quais se verificar a prática de greenwashing poderão caracterizar publicidade enganosa por comissão (artigo $37, \S 1^{\circ}, \mathrm{CDC}$ ), por omissão (artigo $37, \S 3^{\circ}, \mathrm{CDC}$ ) e ainda publicidade abusiva (artigo $37, \S 2^{\circ}, \mathrm{CDC}$ ).

$\mathrm{Na}$ hipótese de constatação de quaisquer dessas espécies de publicidade ilícita, o fornecedor anunciante que se utilizar da prática do greenwashing pode ser alvo de sanções de natureza civil, penal e administrativa, sendo cada uma delas aplicada pela autoridade competente.

Para que se obtenha, na prática, uma maior efetividade no controle de práticas abusivas como o greenwashing na publicidade, propõe-se um conjunto de ações mais contundentes e articuladas dos órgãos que fazem parte do Sistema Nacional de Defesa do Consumidor (SNDC). 
Na seara civil, destaca-se o Poder Judiciário, ao conceder indenizações que sejam suficientes não apenas para reparar os danos causados, mas também para coibir os fornecedores de reincidirem na dita conduta ilícita, seja no âmbito da tutela individual ou coletiva.

No âmbito penal, as delegacias especializadas na defesa do consumidor, devem atuar no sentido de aumentarem a fiscalização a fim de proporcionar mais efetividade na aplicação da legislação penal do consumidor, punindo com mais incidência as condutas caracterizadoras de crimes contra as relações de consumo (v.g., publicidade enganosa e abusiva).

E na esfera administrativa, sugere-se a intensificação das ações dos PROCONs (estaduais e municipais), não apenas no sentido de informar os consumidores, mas também da aplicação de sanções administrativas, e do Ministério Público, propondo ações perante o Poder Judiciário a título de tutela coletiva, bem como celebrando Termos de Ajustamento de Conduta (TAC) com os fornecedores que se utilizarem do greenwashing nos anúncios de seus produtos e serviços.

\section{Referências}

ACOSTA ESTÉVEZ, José B. Tutela procesal de los consumidores. Barcelona: José M. Boch, 1995.

AKTURAN, Ulun. How does greenwashing affect green branding equity and purchase intention? An empirical research. Marketing Intelligence \& Planning. v. 36 n. 7, p. 809824. 2018.

ALVES, Fabrício Germano. Proteção constitucional do consumidor no âmbito da regulação publicitária. Natal: Espaço Internacional do Livro, 2013.

BOTANA GARCÍA, Gema; RUIZ MUÑOZ, Miguel (coord.). Curso sobre protección jurídica de los consumidores. Madrid: McGraw-Hill Interamericana de España S.A.U., 1999.

BRASIL. (Constituição 1988). Constituição da República Federativa do Brasil. Promulgada em 05 de outubro de 1988.

BRASIL. Código Brasileiro de Autorregulamentação Publicitária, de 05 de maio de 1980. Disponível em: http://www.conar.org.br/. Acesso em: 11 jan. 2020.

BRASIL. (Código de Proteção e Defesa do Consumidor). Lei no 8. 078, de 11 de setembro de 1990. Dispõe sobre a proteção do consumidor e dá outras providências.

BRASIL. (Código Civil). Lei n⿳ 10.406, de 10 de janeiro de 2002. Institui o Código Civil.

BRASIL. Secretaria Nacional do Consumidor - SENACON. Departamento de Proteção e Defesa do Consumidor - DPDC. LEMOS, Patrícia Faga Iglecias; SILVA, Juliana Pereira da; 
OLIVA, Amaury Martins (coord.). Consumo sustentável. Brasília: Ministério da Justiça, 2013. Caderno de investigações científicas. v. 3.

CASADO, Márcio Mello. Proteção do consumidor de crédito bancário e financeiro. 2. ed. São Paulo. Revista dos Tribunais, 2006. (Biblioteca de Direito do Consumidor). v. 15.

COELHO, Fábio Ulhoa. O empresário e os direitos do consumidor. São Paulo: Saraiva, 1994.

CORREIA, Luís Brito. Direito da comunicação social: direito de autor e da publicidade. Coimbra: Almedina, 2005. v. II.

CRIVELLARI, Júlio César Teixeira. A prática do greenwashing e o princípio da boa-fé nas relações de consumo. JUS: Revista da Associação Mineira do Ministério Público, Belo Horizonte, ano 43, n. 27, p. 99-108, 2012.

ECOLABEL INDEX. All ecolabels in Brazil. Disponível em:

http://www.ecolabelindex.com/ecolabels/?st=country,br. Acesso em: 10 jan. 2020.

GARCIA, Leonardo Medeiros. Consumo sustentável: a proteção do meio ambiente no Código de Defesa do Consumidor. Salvador: Juspodivm, 2016.

KAMINSKI, Evelyse. Consumo: uma construção identitária cultural na sociedade contemporânea. Revista de estudos da Comunicação. v. 11, n. 24, p. 31-38, jan./abr. 2010.

LAVORENTI, Wilson; GENOFRE, Fabiano; SILVA, José Geraldo da. Leis penais especiais anotadas. 10. ed. Campinas: Millenium, 2008.

LEAL, Augusto Antônio Fontanive. Personalização, consumo e transtornos ambientais.

Revista Prisma Jurídico. São Paulo, v. 18, n. 2, p. 189-207, jul./dez. 2019.

MANUAL de educação para o consumo sustentável. Brasília: Consumers International/MMA/MEC/IDEC, 2005.

MARKET ANALYSIS. Greenwashing no Brasil. 2015. Disponível em: http://marketanalysis.com.br/wp-content/uploads/2015/06/Greenwashing-noBrasil_20151.pdf. Acesso em: 10 jan. 2020.

MÉO, Letícia Caroline. Greenwashing e o Direito do Consumidor: como prevenir (ou reprimir) o marketing ambiental ilícito. São Paulo: Thomson Reuters Brasil, 2019.

MILARÉ, Édis. Direito do Ambiente. 11. ed. São Paulo: Revista dos Tribunais, 2018.

MIRAGEM, Bruno. Curso de Direito do Consumidor. 8. ed. São Paulo: Revista dos Tribunais, 2019.

PAGOTTO, Érico Luciano. Greenwashing: os conflitos éticos da propaganda ambiental. Dissertação (Mestrado). Escola de Artes, Ciências e Humanidades da Universidade de São Paulo: São Paulo, 2013. 
PAIVA, Teresa; PROENÇA, Reinaldo. Marketing verde. São Paulo: Almedina, 2011.

PARGUEL, Béatrice, BENOÎT-MOREAU, Florence; RUSSELL, Cristel Antonia. Can evoking nature in advertising mislead consumers? The power of 'executional greenwashing'. International Journal of Advertising, v. 34, n. 1, p. 107-134. 2015.

PASQUAU LIAÑO, Miguel. Comentário Articulo 8. In: BERCOVITZ RODRÍGUEZCANO, Rodrigo; SALAS HERNÁNDEZ, Javier (coord.). Comentarios a la Ley General para la defensa de los consumidores y usuarios. Madrid: Civitas, 1992.

SANTAELLA LÓPEZ, Manuel. EI delito publicitário: aspectos penales de la comunicación publicitaria. Madrid: Reus, 1981.

SILVA, Juliana Pereira da; OLIVA, Amaury Martins de (coord.). Manual de direito do consumidor. 4. ed. Brasília: Escola Nacional de Defesa do Consumidor, 2014.

SILVA, José Afonso. Direito Ambiental Constitucional. 11. ed. São Paulo: Malheiros, 2019.

TERRACHOICE. Sins of Greenwashing. 2010. Disponível em:

https://www.ul.com/insights/sins-greenwashing. Acesso em: 10 jan. 2020.

THE GUARDIAN. The five: ads banned for greenwashing. Disponível em: https://www.theguardian.com/technology/2020/feb/09/the-five-ads-banned-forgreenwashing.Acesso em: 13 abr. 2020. 